\title{
Biodiversity and landscape diversity as indicators of sustainable development
}

\author{
Sergiy Sonko ${ }^{1}$, Nadiya Maksymenko ${ }^{2}$, Olha Vasylenko $^{1,}{ }^{*}$, Viktoriia Chornomorets $^{1}$, and \\ Iryna $\mathrm{Koval}^{3}$ \\ ${ }^{1}$ Uman National University of Horticulture, Department of Ecology and Safety of Vital Functions, 1 \\ Instytutska str., Uman, 20300, Cherkasy region, Ukraine \\ ${ }^{2}$ Karazin Institute of Environmental Sciences, V. N. Karazin Kharkiv National University, \\ Department of Environmental Monitoring and Nature Use, 6 Svobody sq., 61022, Kharkiv, Ukraine \\ ${ }^{3}$ G. M. Vysotsky Ukrainian Research Institute of Forestry and Forest Melioration, 86 Pushkinska str., \\ 61024 Kharkiv, Ukraine
}

\begin{abstract}
The main purpose of the article is to substantiate the restrictive content of a sustainable development concept and to show how it is implemented in the theoretical foundations of the agriculture. Today, the initial restrictive content of the concept has changed beyond recognition in a continued large-scale consumption of natural resources. Consequently, the very concept of sustainability requires clarification. It is necessary to look for its signs in natural ecosystems, where the main indicator is life itself, maintained by the biosphere in a state of stable dynamic equilibrium. Introducing monoculture, people deliberately impoverish biodiversity in agroecosystems, by transforming natural into agro-landscapes. Adaptive technologies could be the means to achieve a stable balance. In that case, the mechanisms of matter-energy metabolism in agroecosystems will be closer to the biosphere. The article lays out a set of measures through which the use of nature can be closer to general scientific ideas of sustainability.
\end{abstract}

\section{Introduction}

Since the Rio Conference in 1992, a lot has changed in the perception of the sustainable development concept. The concept of sustainable development has been, and still is, subject to criticism, including the question of what is to be sustained in sustainable development. It has been argued that there is no such thing as a sustainable use of a non-renewable resource, since any positive rate of exploitation will eventually lead to the exhaustion of earth's finite stock. First, the number of environmental disasters continues to grow, indicating the areas of nature management [1]. Secondly, the direct consequence of predatory nature management is a gradual loss of biodiversity, which according to many scientists, poses an insurmountable threat to the entire biosphere [2]. Third, at the second and third summits (Johannesburg and Rio +20 ), the emphasis of the concept shifted from the restrictive content, understood by all after Rio 1992, towards the improvement of

\footnotetext{
*Corresponding author: vsolga05@gmail.com
} 
human development [3]. This can be achieved only through further increased consumption of planetary natural resources. Even the later concept of the humankind's ecological footprint [4], indicating the true price of resource consumption, has not changed the situation. The global environmental problems continue to escalate. Thus, the very concept of sustainable development questions the correctness of its theoretical foundations. It is unfortunate that some countries of the world (including Ukraine) rushed to fulfil provisions of this concept, both at the level of the scientific community and state institutions [5].

While mineral resources are more important for developed countries, the problem of self-feeding remains the most pressing for less developed countries [6]. Given that the majority of the world's population lives in the third world countries, the question of agroecosystems' depletion is very acute.

Considering the fact that agroecosystems are still able to feed people due to annual recovery of biomass, natural fertility of land is becoming invaluable capital. Let us say more - this is the resource, that first comes to mind in the definition of a sustainable development: "Sustainable - is a development in which natural resources are sufficient not only for today, but also for future generations" [7].

A derivative, but rather a parallel (along with the loss of soil fertility) manifestation of the agroecosystem's functioning is the loss of bio- and landscape diversity [8]. Thus, the desire to make the most profit involves large fields (for the ease of using agricultural machinery), which initially kills the high diversity inherent in natural landscapes. At the ecosystem level, it destroys the natural habitats of plants and animals, leading to the extinction of about one species per day on the planet [9].

High relevance of our study follows from the extremely important role of agriculture as an industry closest to the biosphere. Therefore, it can be most quickly adapted to its material and energy mechanisms. It is possible to achieve the principles of sustainable development only by adhering to the biosphere laws in nature management.

\section{Methods}

The paper uses a technique, assessing the complexity of the landscape diversity, applying both the general theory of systems and the theory of landscape science. It proposes to assess quantitatively the positional location of landscapes by determining the complexity, entropy, territory organization degree [10]. The final point in assessing landscape mosaic is calculation of the ratio of variegation and homogeneity to the area indicators.

Development of cartographic materials is done with the help of GIS in the desktop geographic information system ArcGIS 10.1.

\section{Results}

Keeping in mind that the path to sustainability of nature management is in agriculture, the following main features of agroecosystems [10] deserve attention:

- the desire for monoculture, which significantly reduces the biodiversity of natural ecosystems in the area. Attempts to "resist" pests and weeds are mainly associated with intensive introduction of chemicals. Since the late twentieth century -with genetic engineering;

- an ecological pyramid, with the man on top, has drastically changed in agroecosystems [10];

- consumption of ecological, geographical and energy resources of the biosphere as the most important feature of agroecosystems cannot contribute to sustainable development. 
According to authoritative estimates, the planet's biosphere is capable of feeding between 500 million and 1 billion people without harming itself [9].

Measurements, carried out in undisturbed natural ecosystems [11], show that large vertebrates (including humans with all domesticated animals) account for less than $1 \%$ of the energy, circulating in the biota. In reality, the human population has already exceeded this $1 \%$ threshold ten times [12]. There are two most powerful sources of natural ecosystems destruction - burning fossil fuels and agricultural activities. In the early 2000s, the second source was almost equal to the first [13]. These figures clearly show the gap in the notion of "sustainability" of modern nature management, forcing us to analyze its natural-scientific foundations.

In view of the above, the authors set themselves the following tasks:

- to explore physical and biological foundations of a "sustainability" concept;

- to prove that it is possible to achieve "sustainability" primarily in agriculture - the industry, closest to the biosphere material and energy mechanisms;

- to study the mechanisms of landscape and biodiversity loss in agrolandscapes of Kharkiv region;

- to suggest ways of agriculture adaptation to biosphere mechanisms of nature use, corresponding to the main principles of sustainable development.

The main hypothesis of our study is assumption of the potential nature management on the principles of sustainable development.

The object of the research is agroecosystems as forms of ecological human existence and those, formed on the site of natural landscapes.

The subject of the study is the mechanisms of agroecosystems' functioning, ensuring restoration of landscape and biodiversity.

The meaning of the term "sustainability" in relation to biota and ecosystems is most thoroughly studied in the works of V. Gorshkov [14]. According to him, living organisms regulate the state of the environment by "compensation" (similar to the principle of Le Chatelier in chemical environments and physical states). Such regulation ensures a sufficiently high level of ecological valence of all species, and creates a certain "reserve" of ecological plasticity in them. According to V. Gorshkov's calculations [14], it is the "burial" of organic carbon in the soil and further in the sedimentary rocks that maintains a constant proportion of oxygen and carbon dioxide in the biosphere.

Since the beginning of the industrial revolution, man has been actively using fossil hydrocarbon compounds (natural gas, coal, oil), wasting the strategic stock of the biosphere, created by it during the geological time. Today, the total anthropogenic share of biosphere products consumption is $10 \%$ (instead of $1 \%$ in the pre-industrial era). According to V. Gorshkov [14], the desire to maximize the productivity of man-made bioresources endangers the the environment. We can deduce the main axiom of sustainable development from the above - sustainability of nature use is possible in such a state of biota and the surrounding environment, in which perturbations are below the threshold of the principle of Le Chatelier.

Thus, sustainability of the biosphere depends on the number and density of species correlation in wildlife. This helps us to better understand the meaning of the term "biodiversity" [10]. Ever since the first reports to the Club of Rome, there have been calls about such an inner meaning in the concept of "Sustainable development" [15]. This problem has finally become a fact of public awareness, increasingly confirmed today [6].

The concepts of growth and development mean to develop, improve and grow, expand. But unlike human economy, the formation and evolution of natural ecosystems is characterized by the phenomenon of development without growth. Any ecosystem in the process of evolution has long been developing only qualitatively, but does not grow wide due to the boundaries of the biosphere. 
The main stimulus for the development of biota is its constant "dialogue" with the external environment and "search" for the most effective mechanisms for its regulation and stabilization.

Biological diversity is a unique feature of wildlife, which ensures the structural and functional organization of ecosystems, maintaining their stability over time and resistance to environmental changes.

The problem of biodiversity is most acute in agriculture because of the attempts to increase yields through monoculture. Attempts to "diversify" the species composition of agrophytocenoses by introducing 9-12-field crop rotations have been offset by the desire to make more profit. Thus, the number of fields in the modern "scientifically sound" crop rotation reaches five. This is in theory [16]. But in reality, most producers leave only three fields in the "crop rotation" - one under the grain, two others - under the technical (mostly row) crops.

As for ecosystems, V.V. Dokuchaev [17] was the last who cared about the observance of proportions in agrolandscapes, corresponding to natural ones. Genetic diversity is the key to the survival of the biosphere under changing environmental conditions, as it provides a high adaptive potential of organisms. The higher the genetic heterogeneity, the greater the variability of physiological and ethological reactions of the organism is. Genetic diversity is the basis for natural selection due to which the body has more chances to survive.

The species level of biodiversity is based on the fact that the richest species of communities are more stable through the implementation of various types and forms of biotic relationships - topical, foric, factory, trophic. Therefore, the removal of at least one species from the ecological system can lead to its destabilization, disruption of homeostasis and, as a consequence, death.

In the world agricultural practice, reduction of species diversity is directly derived from simplification of agrolandscapes spatial structure, as the latter provides ecotopes to all species in ecosystems. For comparison, Fig. 1 shows the spatial structure of natural and agroecosystems.

We studied the forest-steppe part of Kharkiv region to establish the level of landscape diversity at the experimental landfill [11].
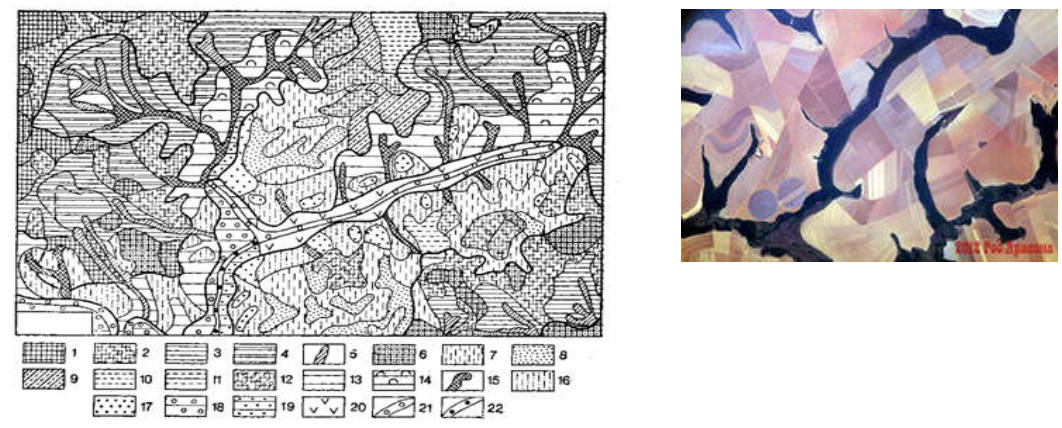

Fig. 1. On the left - a map of high spatial discreteness of natural ecosystems; on the right - a space image of the correct contours of crop rotation fields in agroecosystems.

Fig. 2 shows that $67.3 \%$ of the landfill area are agrolandscapes, rural settlements $9.9 \%$, urban landscapes $-5 \%$ and only $2.5 \%$ - are protected, $13.8 \%$ - forestry and $1.6 \%-$ water management landscapes, which partially retain the features of landscape and biodiversity. 


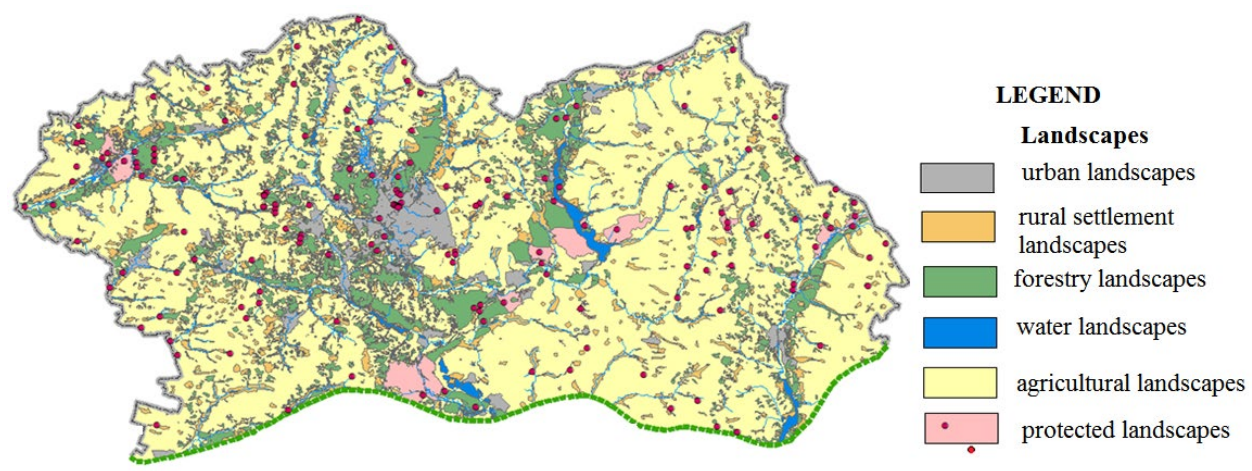

Fig. 2. Landscape differentiation of Kharkiv landfill territory.

We propose to use the mosaic coefficient to describe the landscape diversity. The territory in it is completely mosaic when there is an equal probability distribution of a large number of varieties and their uniform distribution in the territory [18].

By "large number" we mean " a number of features that the complexity of this area is equal to one. The calculations showed that for the agricultural firm "Korobochkine" (Fig. 3) the mosaic coefficient was 0.28 , for Chuguiv district -0.34 , i.e. there is a significant deviation from one, indicating a low landscape diversity of the territory.

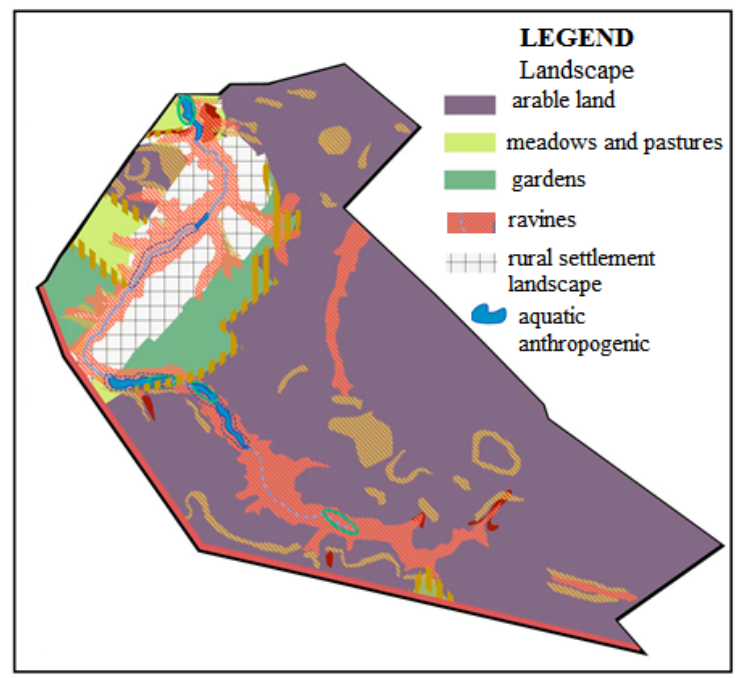

Fig. 3. Landscapes of the agricultural firm "Korobochkino".

At the beginning of the twentieth century, the great reformer P.A. Stolypin insisted that only small and medium-sized peasant farms could not only produce marketable agricultural products, but also take good care of the land, inherited from father to son [19].

Agriculture can negatively affect the environment by the following:

- fundamental changes in the structure and spatial organization of natural landscapes, "entailing" the rest of the ecologically negative impacts due to the greatest "conservatism" of the lithogenic basis (geological structure + relief). If changed once, it will be almost impossible to restore; 
- reduced agrophytocenoses resistance due to the use of monoculture and fundamental changes of natural ecosystems, leading to simplification of species structure (loss of biodiversity);

- reduction of natural soil fertility due to the loss of humus and the need to use higher doses of NPK.

\section{Discussion}

The closest to the level of "sustainability" are the systems and methods of agriculture that return people to dialogue with the biosphere [6]. Modern "no-till" technology allows future generations to have a sufficiently fertile soil and to prevent $\mathrm{CO}_{2}$ emissions [20]. Many areas in the forest-steppe and steppe zone of Ukraine are prone to water and wind erosion. The plants, left in the field, absorb all the energy of the rain, let the water into the soil and save it from evaporation. A unique agroecosystem is formed on the principles of polyculture, inter-row and mixed sowing. Precision farming is implemented in two modes - "off-line" and "on-line". The first involves preliminary preparation of the task map. To do this, we collect the required data on the field from soil analyses. Then the task card is transferred to the on-board computer of the tractor, equipped with the GPS receiver, and special equipment carries out the set operation.

The second mode ("on-line") involves determining the agricultural needs of plants in a particular area of the field, using special sensors (which determine nitrogen content in the leaves, littering of crops, assess biomass) directly during the operation. The on-board computer receives data from the sensor, compares them with the stored agricultural needs and sends a signal to the controller, which opens the nozzles at the right time [10].

Organic crop production is a form of management, involving minimum use of synthetic agrochemicals. Instead, they use biological methods: introduction of natural enemies and specific pathogens, crop rotations, based on the development cycle of the pest, appropriate tillage.

Biodynamics is a modern effective technology that involves not only soil fertilizing, but also feeding the countless inhabitants, living in it. The principle of biocompatibility of plants, producing different substances, is important. Therefore, mixed crops and polyculture are very relevant. "Wilding" one of the remote areas of the farm can become a habitat for hedgehogs, birds and other natural enemies of pests, preventing their spread, typical for intensive agriculture.

Vermitechnology is breeding of compost worms (and artificially bred hybrids California, "digger", Dendrobeana) whose food source are plant residues. They contribute to the accumulation of organic matter, forming biohumus (vermicompost) - an environmentally friendly organic fertilizer. Biohumus is $4-8$ times superior to manure and compost in terms of humus content.

Practical use of these ecologically tolerant methods is possible, provided a return to small and medium-sized farms. This is very important on the eve of the land market introduction. Under these conditions, the peasant family, as the owner of this land, will be interested not only in obtaining the maximum yields, but also in maintaining maximum soil fertility (inherited by children). Moreover, the landscape and biodiversity, supporting the natural fertility of soils, will be not only a condition of human management, but also its main result in the agrosphere. Afterward, it will be possible to talk about the implementation of sustainable development ideas in nature management.

Landscape is the initial level on the complex path of anthropogenic transformation of material and energy flows of the biosphere. It would be logical to consider the depth of natural landscapes transformation into anthropogenic (agrolandscapes) as one of the most effective indicators of sustainable development. 


\section{Conclusions}

The main results of the study include:

1. Theoretical substantiation of the restrictive content of a sustainable development concept, in particular:

- The "stability" of the biosphere depends on the number and density of correlation of species in the wild. That is why the desire for biodiversity, even in artificially created agroecosystems, should be considered as the main condition for sustainable development;

- According to the research results of landscape and biodiversity reduction mechanisms (a case of agrolandscapes of Kharkiv region), we propose to include the loss degree of natural landscapes diversity (in the form of the corresponding coefficient) in the list of main indicators of sustainable development;

2. Practical introduction of the authors' approaches to modern resource-intensive agriculture in order to bring it closer to biosphere mechanisms, in particular:

- The path to sustainability of all nature management is in agriculture as it provides the simplest, but most essential and everyday human needs. We can compare our species with others in the biosphere on ecological grounds, and, therefore, approximate nature use to biosphere mechanisms.

- The effective systems and technological methods of agriculture, closest to the level of "sustainability", are those that return people to dialogue with the biosphere, namely, "notill" -technology, precision farming, and various areas of environmental conversion.

\section{References}

1. The Future We Want Rio+20 Outcome Document. (2012). https://www.slideshare.net/uncsd2012/the-future-we-want-rio20-outcome-document

2. Gonzalez, A., Cardinale, B. J., Allington, G. R. H., Byrnes, J., Arthur, E. K., Brown, D. G., Hooper, D. U., Isbell, F., O'Connor, M. I., Loreau, M. (2016). Estimating local biodiversity change: a critique of papers claiming no net loss of local diversity. Ecology. 97 (8), 1949-1960. https:// doi:10.1890/15-1759.1

3. Almond, R.E.A., Grooten, M., Petersen, T. (Eds). (2020). Living Planet Report 2020 Bending the curve of biodiversity loss. https://www.zsl.org

4. Lin, D., Hanscom, L., Murthy, A., Galli, A., Evans, M., Neill, E., Mancini, M.S., Martindill, J., Medouar, F-Z., Huang, S., Wackernagel, M. (2018). Ecological Footprint Accounting for Countries: Updates and Results of the National Footprint Accounts, 2012-2018. Resources, 7(3), 58. https://doi.org/10.3390/resources7030058

5. Verkhovna Rada of Ukraine. (2019). About Aims of steady development of Ukraine on a period 2030 to. Decree of President of Ukraine № 722/2019. https://zakon.rada.gov.ua/laws/show/722/2019\#Text

6. United Nations Environment Programme. (2021). Making Peace with Nature: A scientific blueprint to tackle the climate, biodiversity and pollution emergencies [Fact sheet]. https://www.unep.org/resources/making-peace-nature

7. Holden, E., Linnerud, K., Banister, D. (2014). Sustainable development: Our Common Future revisited. Global Environmental Change, 26, 130-139. https://doi.org/10.1016/j.gloenvcha.2014.04.006

8. Poppenborg, M. E., Feit, B., Requier, F., Friberg, H., Jonsson, M. (2019). Assessing the resilience of biodiversity-driven functions in agroecosystems under environmental change. Advances in Ecological Research, 59-123. https://doi.org/10.1016/bs.aecr.2019.02.003 
9. Insurance information institute. (2020). Facts + Statistics: Global catastrophes [Fact sheet]. https://www.iii.org

10. Sonko, S. P., Maksymenko, N. V. (Eds.). (2015). Ecological bases of balanced nature use in agrosphere. V.N. Karazin Kharkiv National University.

11. Díaz, S., Settele, J., Brondízio, E. S., Ngo, H. T., Guèze, M., ...... Willis, K. J. (Eds.). (2019). IPBES: Summary for policymakers of the global assessment report on C. N. biodiversity and ecosystem services of the Intergovernmental Science-Policy Platform on Biodiversity and Ecosystem Services. IPBES secretariat.

12. Bar-On, Y. M., Phillips, R., Milo, R. (2018). The biomass distribution on Earth. PNAS, 115 (25), 6506-6511. https://doi.org/10.1073/pnas.1711842115

13. Candela, J., Carlson, D. (2017). The Annual Global Carbon Budget. WMO. Bulletin, 66 (1).

14. Gorshkov, V., Makarieva, A. (2018). Time in life, technology and physics. https://doi.org/10.13140/RG.2.2.35964.59528

15. Bobylev, S. (2017). Sustainable Development: Paradigm for the Future. World economy and international relations, 61 (3), 107-113.

16. Yeschenko, V. O. (2014). The place of scientifically grounded crop rotations in modern agriculture. Bulletin of Uman National University of Horticulture, 2, 3-7.

17. Harmasar, V. G. (2018). The significance of scientific "Duchachev" expeditions in the history of the development of contemporary natural science. Questions of the history of science and technology, 2, 46-54.

18. Maksymenko, N. V. (2013). Methodical going near estimation of land scape mosaicism of territory. Man and environment. Issues of Neoecology, 1-2, 28-33. https://periodicals.karazin.ua/humanenviron/ article/view/955

19. Borisov, M. Y. (2016).Actual features of Stolypin's agrarian reform. History of national economy and economic thought of Ukraine, 49, 79-92.

20. Graham, M., Thomas, R., Lombardozzi, D., O'Rourke, M. (2021). Modest capacity of no-till farming to offset emissions over 21 st century. Environmental Research Letters. https://doi.org/10.1088/1748-9326/abe6c6 